\title{
Study of Growth Pattern in School Children of Both Genders Aged Between 9 and 12 Years.
}

\author{
Kharat Vidya Shankarrao ${ }^{1}$, Puranik Medha ${ }^{2}$, Garud Rajendra ${ }^{3}$ \\ ${ }^{I}$ (Assist. Prof. Department of Anatomy, Bharati Vidyapeeth Deemed University \\ Medical College and Hospital, Pune, Maharashtra, India) \\ ${ }_{2}^{2}$ (Prof. Department of Anatomy, Bharati Vidyapeeth Deemed University \\ Medical College and Hospital, Pune, Maharashtra, India) \\ ${ }^{3}$ (Prof. Department of Anatomy, Bharati Vidyapeeth Deemed University \\ Medical College and Hospital, Pune, Maharashtra, India
}

\begin{abstract}
The aim of the present study was to comprehend the growth pattern of school children in the age group of 9-12 years, inclusive of both sexes, belonging to Higher Income Group (HIG) and Lower Income Group (LIG) groups. The study was carried on total 511 school children in Pune, India. The Anthropometric measurements of body height and weight, belonging to both genders, and contrasting socioeconomic groups were obtained and studied by cross sectional analysis.

We observed that values of all parameters of HIG were almost greater than LIG values in all the age groups. This lag in the LIG values could be due to constant exposure to severe nutritional, social and environmental strain. Girls of both HIG and LIG showed growth spurt in height earlier than boys of HIG and LIG. We made an interesting observation that minimum value of weight at the age group of 9-10 years of HIG were corresponding with the maximum values of weight at 11-12 years of LIG.

The data would be useful to understand the growth pattern in school children of age group of 9-12 years as influenced by the socio-economic factors.
\end{abstract}

Keywords: Anthropometry, Growth pattern, Socio-economic groups.

\section{Introduction}

Growth assessment is an essential component of health surveillance and the gold standard for growth assessment is anthropometric measurements. The term 'Growth and Development' used in the studies of physical growth is referred as a process not only intimately linked with time but also affected by genetic factors, environmental factors like socio-economic status, demographic factors like race \&sex,nutritional factors, physical factors like climate and pollution, biological factors like infections, drugs, chemicals \& emotional factors [1].The adolescent phase of the growth is equally important as childhood growth. Physiological changes during this period contribute immensely to the growth differences among the boys and girls. Physical outcome in growth, form and shape manifest differently between both sexes. There is therefore a need to study the pattern of physical growth in terms of growth dynamics, which work differently in each individual as among the males (boys) and females (girls).Growth in height continues at a slower rate after adolescent growth spurt [2] In India, socio-economic differences are highly prevalent and it is expected that such differences in the form of food resources would finally have their influence on growth outcome.

Present study tried to understand the growth differences with the help of Anthropometric parameters, among two contrasting socio-economic groups of school children in Pune city.

\section{Material And Method}

The cross-sectional study as seen in table 1 was carried on total 511 subjects, males -252 , females- 259 inclusive of both sexes and both higher socio-economic status / higher income group (HIG) and lower socioeconomic status /lower income group (LIG)

Cross-sectional studies are valuable for construction of standards for height and weight attained by healthy children at specific ages [3].Ideally it was necessary to decide the economic status of each subject. However, it was extremely difficult to carry out such a survey because students as subjects for this study were not in a position to give their family income correctly. Thus it was decided to select those schools (Corporation /Municipal schools) in slum areas in Pune, where the students belonged to the Lower socio-economic status /Lower income group (LIG) where they generally opt to enroll. The English medium schools, in elite areas in Pune, on the contrary have majority of students who belonged to the upper and middle class families/Higher socio- economic status /higher income group (HIG) with high income.

Standing body height vertex was measured by anthropometric rod where the bare footed subject was asked to stand in normal anatomical position, the sliding limb of the anthropometer was lowered till it touched the 
Study Of Growth Pattern In School Children Of Both Genders Aged Between 9 And 12 Years.

highest point on the top of the head (vertex), in the mid-sagittal plane. The height was measured in centimeters.Weight was measured with a weight beam scale in kilograms with daily clothes on and barefooted

\section{Results}

The study was carried out on total 511 subjects of both sexes from the age group of $9-12$ years and were considered separately for both HIGand LIG as well as for sex differences.

Table 1: Cross-sectional study

\begin{tabular}{|l|c|c|c|c|}
\hline \multirow{2}{*}{ Age (yrs.) } & \multicolumn{2}{|c|}{ Male } & \multicolumn{2}{c|}{ Females } \\
\cline { 2 - 5 } & HIG & LIG & HIG & LIG \\
\hline $9-10$ & 42 & 42 & 42 & 42 \\
\hline $10-11$ & 42 & 42 & 42 & 42 \\
\hline $11-12$ & 42 & 42 & 42 & 49 \\
\hline Total & 126 & 126 & 126 & 133 \\
\hline
\end{tabular}

\section{Height vertex:}

The analysis of individual parameters was as follows (Table 2, Graph 1).There was an increase in height vertex values from $9-12$ years in both LIG and HIG. The values of height vertex in H.I.G.were higher in 9 to $10,10-11 \& 11-12$ years compared to L.I.G.Girls of HIG and LIG showed growth spurt (maximum increase) in height at $10-11$ years. Boys of both HIG and LIG showed growth spurt in height at $11-12$ years of age. Thus girls of both HIG and LIG showed growth spurt in height earlier (10-11 years), than Boys of HIG and LIG (11 - 12 years).

Table 2 Height Vertex $(\mathrm{cm})$

\begin{tabular}{|c|c|c|c|c|c|c|c|}
\hline \multicolumn{2}{|c|}{$\begin{array}{c}\text { Height vertex } \\
\text { cm }\end{array}$} & \multicolumn{2}{c|}{ 9-10yrs } & \multicolumn{2}{c|}{ 10-11yrs } & \multicolumn{2}{c|}{ 11-12yrs } \\
\cline { 2 - 8 } & Males & Females & Males & Females & Males & Females \\
\hline \multirow{2}{*}{ LIG } & Mean & 116.18 & 116.61 & 121.26 & 121.98 & 132.72 & 126.49 \\
\cline { 2 - 8 } & S.D & 5.59 & 6.85 & 6.84 & 7.18 & 7.05 & 7.24 \\
\hline \multirow{2}{*}{ HIG } & Mean & 133.43 & 129.07 & 136.34 & 140.01 & 141.97 & 143.79 \\
\cline { 2 - 8 } & S.D. & 5.17 & 3.61 & 5.77 & 6.05 & 4.62 & 4.98 \\
\hline
\end{tabular}

S.D. - Standard Deviation

\section{Distribution of Height Vertex $(\mathrm{cm})$ in Males \& females According to Age and Socio-Economic Status}

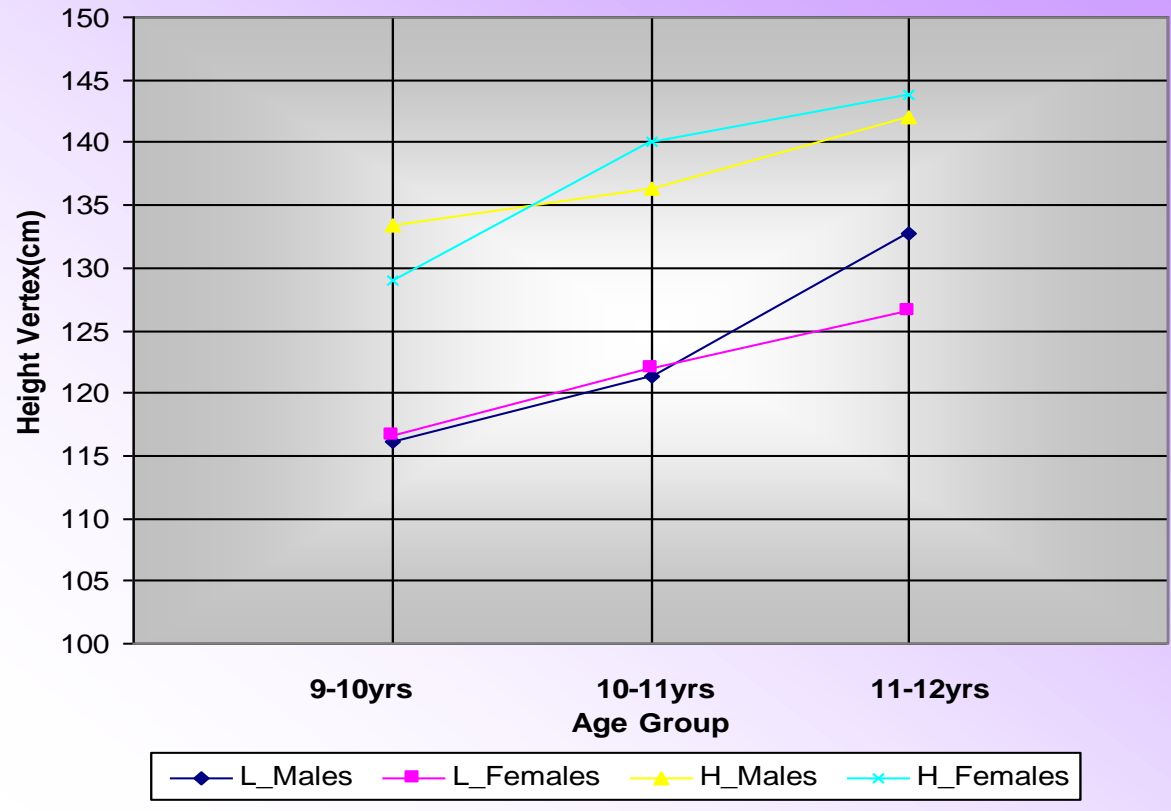

Graph 1: Height vertex (cms)

Weight: 
The analysis of individual parameters was as follows (Table 3 .Graph 2). There was a clear difference in measurement of Weight in HIG and LIG groups. The HIG showed more increase in values compared to LIG in both girls and boys groups. The mean weight seen in the girls of HIG at 9-10 years was $28.14 \mathrm{~kg}$, which increased with a growth spurt to 34.06 at 10-11 years. This increase in weight was maintained in the next age group of females of 11-12 years to $35.61 \mathrm{~kg}$. The mean weight seen in boys of HIG at 9-10 years was $27.66 \mathrm{~kg}$, which increases with a growth spurt to $33.94 \mathrm{~kg}$ at $10-11$ years. This increase in weight was maintained in the next age group of boys of 11-12 years to $34.08 \mathrm{~kg}$.

In girls of LIG there was a steady increase in values in weight from $9-12$ yrs. The growth spurt in girls of LIG was seen at $11-12$ yrs $(28.20 \mathrm{~kg})$. In boys of LIG at $9-10$ yrs weight was $22.59 \mathrm{Kg}$, which decreased to $21.67 \mathrm{Kg}$ at $10-11$ years. The boys in the age group of $11-12$ years showed an increase in weight to $25.65 \mathrm{~kg}$. Thus the boys in LIG age group of $11-12$ showed a growth spurt.The decrease in weight in LIG group of boys at 10 - 11 age group could be explained on the basis that the study was cross sectional.Growth spurt in weight in the girls of HIG was seen earlier at $10-11$ years and in LIG females growth spurt in weight is seen at $11-12$ years. It was observed in this present study that minimum values of weight at 9 -10 years of HIG were corresponding to the maximum values of weight at $11-12$ years of LIG.

Table 3:Weight $(\mathrm{Kg})$

\begin{tabular}{|l|l|c|c|c|c|c|c|}
\hline \multirow{2}{*}{$\begin{array}{l}\text { Weight } \\
\text { Kg }\end{array}$} & \multicolumn{2}{|c|}{ 9-10yrs } & \multicolumn{2}{c|}{$\mathbf{1 0 - 1 1 y r s}$} & \multicolumn{2}{c|}{ 11-12yrs } \\
\cline { 3 - 8 } & Males & Females & Males & Females & Males & Females \\
\hline \multirow{2}{*}{ LIG } & Mean & 22.59 & 20.55 & 21.67 & 22.45 & 25.65 & 28.20 \\
\cline { 2 - 8 } & S.D & 2.83 & 2.79 & 3.29 & 3.31 & 3.84 & 6.10 \\
\hline \multirow{2}{*}{ HIG } & Mean & 27.66 & 28.14 & 33.94 & 34.06 & 34.08 & 35.61 \\
\cline { 2 - 8 } & S.D. & 5.90 & 4.48 & 6.22 & 6.47 & 6.71 & 6.99 \\
\hline
\end{tabular}

S.D. - Standard Deviation

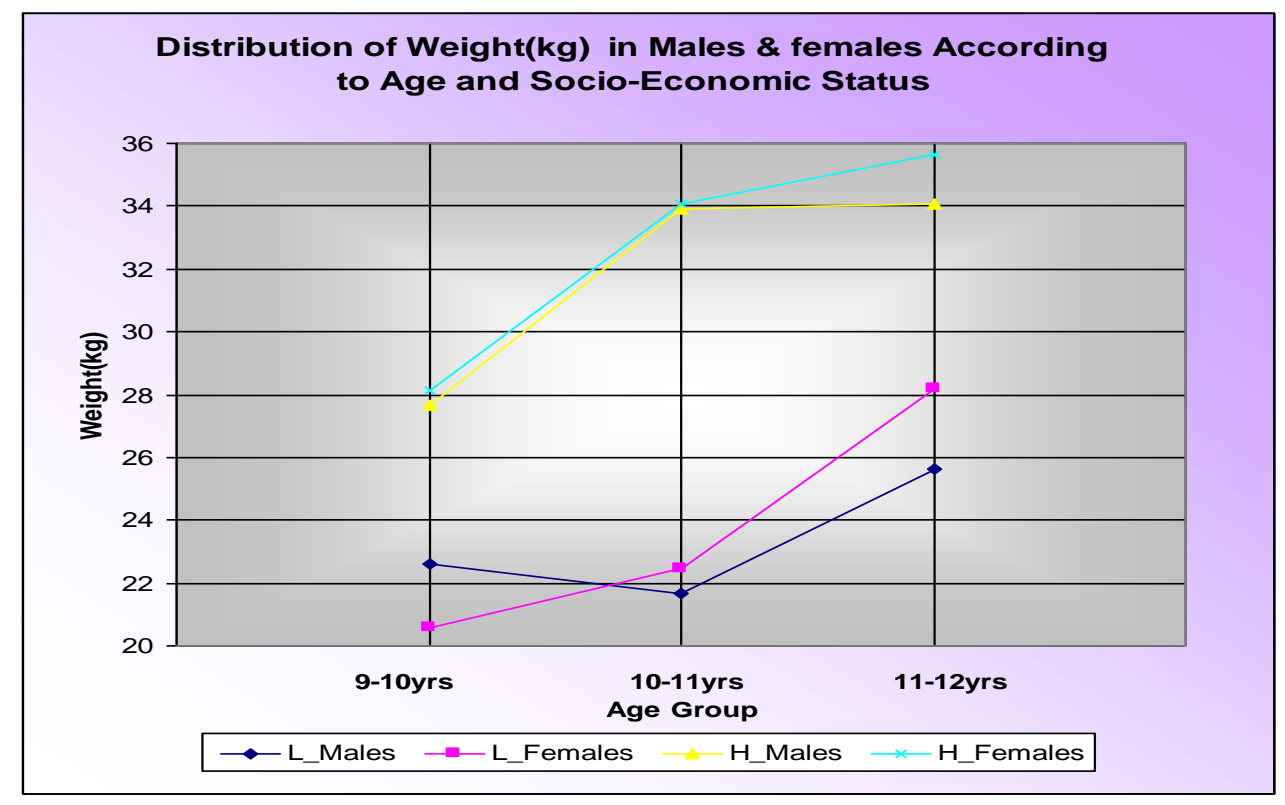

Graph 2: Weight $(\mathrm{kg})$

L - Lower Socio-economic group (LIG), H - Higher Socio-economic group (HIG)

All the data in the present study was analyzed statistically by applying ' $Z$ ' test for significance and is presented in table no $4 \& 5$.

Table 4:Z-test for the comparison between the Low and High Socio-economic group children.

\begin{tabular}{|c|c|c|c|c|}
\hline \multicolumn{3}{|c|}{ Comparison Between LOW and HIGH socio-economic group } & \multirow{2}{*}{$\begin{array}{c}\text { Weight } \\
9.60\end{array}$} & \multirow{2}{*}{$\begin{array}{c}\text { Height } \\
6.06\end{array}$} \\
\hline \multirow{6}{*}{ 9-10 yrs. } & \multirow{3}{*}{ Males } & Z value & & \\
\hline & & p-value & 0.00 & 0.00 \\
\hline & & Significance & HS & HS \\
\hline & \multirow{3}{*}{ Females } & $\mathbf{Z}$ value & 8.88 & 8.86 \\
\hline & & p-value & 0.00 & 0.00 \\
\hline & & Significance & HS & HS \\
\hline \multirow{3}{*}{ 10-11 yrs. } & \multirow{3}{*}{ Males } & $Z$ value & 8.47 & 11.9 \\
\hline & & p-value & 0.00 & 0.00 \\
\hline & & Significance & HS & HS \\
\hline
\end{tabular}


Study Of Growth Pattern In School Children Of Both Genders Aged Between 9 And 12 Years.

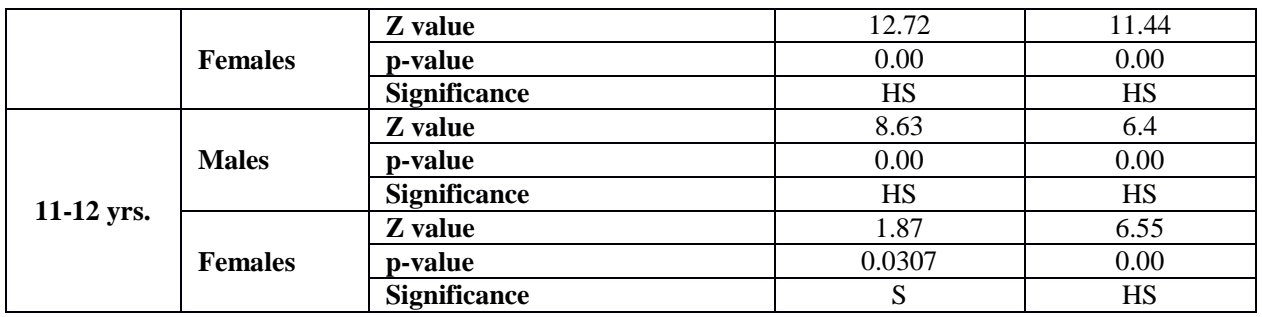

HS: Highly Significant,S: Significant Since p-value $<0.05$, there is significant difference between the Low and High Socio-economic group Children

Table no. 5-Z-test for the comparison between the Males and Females

\begin{tabular}{|c|c|c|c|c|}
\hline \multicolumn{3}{|c|}{ Comparison Between Males \& Females } & Weight & Height \\
\hline \multirow{6}{*}{ 9-10 yrs. } & \multirow{3}{*}{ LIG } & $Z$ value & 2.4 & 0.9 \\
\hline & & p-value & 0.00 & $0 . .70$ \\
\hline & & Significance & HS & NS \\
\hline & \multirow{3}{*}{ HIG } & $Z$ value & 1.3 & 6.32 \\
\hline & & p-value & 0.59 & 0.00 \\
\hline & & Significance & NS & HS \\
\hline \multirow{6}{*}{ 10-11 yrs. } & \multirow{3}{*}{ LIG } & $\mathrm{Z}$ value & 1.7 & 1.2 \\
\hline & & p-value & 0.009 & 0.20 \\
\hline & & Significance & HS & NS \\
\hline & \multirow{3}{*}{ HIG } & $\mathrm{Z}$ value & 1.1 & 5.18 \\
\hline & & p-value & 0.22 & 0.00 \\
\hline & & Significance & NS & $\mathrm{HS}$ \\
\hline \multirow{6}{*}{ 11-12 yrs. } & \multirow{3}{*}{ LIG } & $Z$ value & 6.4 & 4.74 \\
\hline & & p-value & 0.00 & 0.00 \\
\hline & & Significance & $\mathrm{HS}$ & $\mathrm{HS}$ \\
\hline & \multirow{3}{*}{ HIG } & $Z$ value & 3.2 & 4.23 \\
\hline & & p-value & 0.00 & 0.00 \\
\hline & & Significance & $\mathrm{HS}$ & $\mathrm{HS}$ \\
\hline
\end{tabular}

HS: Highly Significant,S:Significant, NS: Not significant since p-value $<0.05$, there is significant difference between Males and Females.

\section{Discussion}

Great diversity in socio-economic status is expected in a developing country like India which would further reflect on the growth pattern of the children. Knowledge of growth pattern of the children is therefore imperative. Healthy children apart from developing into healthy adults and parents can also play a key role in social and health education of their younger sibling and uneducated parents. Studies of growth and development of children in a community provide important information about the nutritional status of the community.

Adolescence is a period of rapid growth. It is a transitional stage in human life [1]. The accurate assessment of physical growth and development of children has recently created interest in the pediatricians and public health officers. In the developing countries growth parameters of a child are now widely recognized as a sensitive index of health and nutrition of the population. W.H.O. has also emphasized upon the health programs of pre pubertal and adolescent boys as well as girls. The data would assist in preparation of various health programs. [4]

In India ,one of the earliest studies were done by Risley H H (1915) on Oraon tribes of Madhya Pradesh and Chatterjee B K (1955) on Kol tribes of Madhya Pradesh [5].Indian Council of Medical Research (ICMR, 1960) had published the report on the growth and development of Indian infants and children. Singh R (1970) [6] carried out a study among Punjabi Hindu Khatri boys of age 11-18 years. Height, weight, sitting height and height minus sitting height were measured. Distance and velocity curves were plotted. Interesting observation of this study was that up to 13 years of age the lower portion of the body grows faster and after 13 years the upper portion grows faster. Gupta, Murthy, Tiwari, and Marwah (1974)[7] studied co-relation of height, weight and mid-arm circumference in infants. There was positive co-relation in these parameters. Influence of socio-economic factors was confirmed by studies of Currimbhoy L (1963) [8]Phadke M V (1968)on Bombay children[9], Mohanta K D (1972) [10]on children of Orissa, Bhandari et al (1972) [11]on Udaipur children, Vijayraghavan, Singh and Swaminathan (1974) on Hydrabad children [12], Agarwal et al (1974)[13]on Varanasi children and Bhasin S K et al (1990) [14]on Haryana children. Agarwal et al (1974) concluded that the optimum growth potential of our well-fed children, could compare favorably with those of western counterparts. N.K.Dutta et al. [15]studied growth pattern of Indian school children in relation to nutrition and adolescence Nag A, Nag P K and Chintharia S G (1987)[16] studied co-relation of height, 
Study Of Growth Pattern In School Children Of Both Genders Aged Between 9 And 12 Years.

weight, mid-arm circumference of women with age. K.E.Elizabeth (2002) [1] gave a detailed information on nutrition and child development along with classification of socio-economic status. Mahajan B K and Gupta M C (2003) [17] gave the classification of economic status which was used in the present study to co-relate growth rate with socio- economic status. Satpati Chatterjee (1991) [18] studied the growth pattern in girls in the age group 10-15 years. He established the growth pattern with respect to height and weight. He found that maximum growth spurt in height was in the age group 10-11 years Better socioeconomic and living conditions, optimal health care, and adequate nutrition brings better health has been observed by many workers." [19]Children of Low socio-economic income group lag very much behind the High socio-economic group. These underprivileged children are constantly exposed to severe nutritional, social and environmental strains as revealed in the present study and the studies done earlier. India has diverse population of having racial, dietary and economic differences.

In this context, using Western standards may have the inherent drawback as children are living under different environment and belonging to a different racial stock. Therefore in the present study, the data was compared with Indian researchers who have done their research on Indian population.

Table no 6:Comparisonof height vertex with other similar studies:

\begin{tabular}{|c|c|c|c|c|c|c|c|c|c|c|c|c|}
\hline \multirow{3}{*}{$\begin{array}{c}\text { Age } \\
\text { Group } \\
\text { (yrs.) }\end{array}$} & \multicolumn{4}{|c|}{$9-10$} & \multicolumn{4}{|c|}{$10-11$} & \multicolumn{4}{|c|}{$11-12$} \\
\hline & \multicolumn{2}{|c|}{ HIG } & \multicolumn{2}{|c|}{ LIG } & \multicolumn{2}{|c|}{ HIG } & \multicolumn{2}{|l|}{ LIG } & \multicolumn{2}{|c|}{ HIG } & \multicolumn{2}{|c|}{ LIG } \\
\hline & M & $\mathbf{F}$ & M & $\mathbf{F}$ & $\mathbf{M}$ & $\mathbf{F}$ & M & $\mathbf{F}$ & M & $\mathbf{F}$ & M & $\mathbf{F}$ \\
\hline $\begin{array}{l}\text { Present } \\
\text { Study }\end{array}$ & 133.43 & 129.07 & 116.18 & 116.61 & $\begin{array}{c}136 . \\
34\end{array}$ & $\begin{array}{c}14 \\
0.0 \\
1\end{array}$ & 121.26 & $\begin{array}{l}121 \\
.98\end{array}$ & 141.77 & $\begin{array}{c}143.7 \\
9\end{array}$ & $\begin{array}{c}132.7 \\
2\end{array}$ & $\begin{array}{c}126.4 \\
9\end{array}$ \\
\hline $\begin{array}{l}\text { M V } \\
\text { Phadke } \\
1967 \\
\end{array}$ & - & - & - & - & $\begin{array}{c}128 . \\
9\end{array}$ & $\begin{array}{l}12 \\
9.7\end{array}$ & 127.2 & $\begin{array}{c}127 \\
.2\end{array}$ & - & - & - & - \\
\hline $\begin{array}{c}\text { Bhandari } \\
1971\end{array}$ & $\begin{array}{c}118.4 \pm \\
20.1\end{array}$ & - & & - & $\begin{array}{c}124 . \\
1 \pm \\
23\end{array}$ & - & & - & $\begin{array}{c}130.2 \pm 1 \\
5\end{array}$ & - & - & - \\
\hline $\begin{array}{c}\text { N Datta } \\
1972\end{array}$ & 133.84 & 132.05 & 127.05 & 126.04 & $\begin{array}{c}138 . \\
58\end{array}$ & $\begin{array}{c}13 \\
7.0 \\
9 \\
\end{array}$ & 131.80 & $\begin{array}{l}130 \\
.62\end{array}$ & 143.06 & $\begin{array}{c}143.9 \\
4\end{array}$ & $\begin{array}{c}136.7 \\
3\end{array}$ & $\begin{array}{c}136.2 \\
5\end{array}$ \\
\hline $\begin{array}{c}\text { S } \\
\text { Chatterje } \\
1991\end{array}$ & - & - & - & $\begin{array}{c}126.49 \pm \\
5.05\end{array}$ & - & - & - & $\begin{array}{r}131 \\
.66 \\
\pm 5 \\
56 \\
\end{array}$ & - & - & - & $\begin{array}{c}137.2 \\
9 \pm 6.2 \\
1\end{array}$ \\
\hline
\end{tabular}

In present study Height vertex was studied in the three age groups of $9-10,10-11$ and $11-12$ years of males and females belonging to H.I.G. and L.I.G. All the values of all the age groups in HIG were greater than that of the LIGage group of $10-11$ years, selected by M. V. Phadke [9] values of HIG were less than that of the present study .Values of LIG of M.V. Phadke were greater than present study. In studies of N. Dutta [15] in Bengali children, values for Height vertex in LIG group are slightly higher than in Pune (present study). The values in HIG group were almost same as in Pune. Bhandari [11] studied males in $9-10,10-11, \& 11-12$ in HIG age groups. Their values in HIG groups were lower than our values. S.Chatterjee [18] studied females in 9 $-10,10-11, \& 11-12$ in LIG groups which showed higher values in LIG group than our values

Table no 7:Comparison of weight with other similar studies

\begin{tabular}{|c|c|c|c|c|c|c|c|c|c|c|c|c|}
\hline \multirow{3}{*}{$\begin{array}{l}\text { Age } \\
\text { Group } \\
\text { (yrs.) }\end{array}$} & \multicolumn{4}{|c|}{$9-10$} & \multicolumn{4}{|c|}{ 10-11 } & \multicolumn{4}{|c|}{$11-12$} \\
\hline & \multicolumn{2}{|c|}{ HIG } & \multicolumn{2}{|c|}{ LIG } & \multicolumn{2}{|c|}{ HIG } & \multicolumn{2}{|l|}{ LIG } & \multicolumn{2}{|c|}{ HIG } & \multicolumn{2}{|c|}{ LIG } \\
\hline & M & $\mathbf{F}$ & M & $\mathbf{F}$ & M & $\mathbf{F}$ & M & $\mathbf{F}$ & M & $\mathbf{F}$ & $\mathbf{M}$ & $\mathbf{F}$ \\
\hline $\begin{array}{l}\text { Present } \\
\text { Study }\end{array}$ & 27.66 & 28.14 & 22.59 & 20.55 & 33.94 & 34.06 & 21.67 & 22.45 & 34.08 & 35.61 & 25.65 & 28.20 \\
\hline $\begin{array}{l}\text { M V } \\
\text { Phadke } \\
1967 \\
\end{array}$ & - & - & - & - & 23.3 & 23.0 & 21.3 & 21.8 & - & - & - & - \\
\hline $\begin{array}{l}\text { Bhandar } \\
\text { i } 1971\end{array}$ & 20.30 & & & & 20.2 & & & & 25.0 & & & \\
\hline $\begin{array}{c}\text { N Datta } \\
1972\end{array}$ & 28.85 & 27.82 & 25.27 & 24.68 & 31.55 & 30.37 & 27.43 & 27.02 & 34.06 & 34.48 & 29.06 & 28.27 \\
\hline $\begin{array}{c}\text { S } \\
\text { Chatterj } \\
\text { e } 1991\end{array}$ & - & & & $\begin{array}{c}21.7 \pm 2 \\
.8\end{array}$ & & & & $\begin{array}{l}24.47 \\
\pm 2.62\end{array}$ & & & & $\begin{array}{l}27.47 \\
\pm 3.88\end{array}$ \\
\hline
\end{tabular}

Comparison of weight with other similar studies (Table no 7):There was obvious weight gain in both the HIG and in LIG groups in the age group of $10-11$ years there was a decrease in weight.The values of M. V.Phadke [9] \& Bhandari [11] studies of HIG were less than values in our HIG but the values of LIG of Phadke studies were similar to our group. There was negligible difference in values of LIG of M.V. Phadke and our study. 
In High income group (HIG) -The weight in the age group of $9-10 \& 11-12$ group in present study and Dutta were comparable .But in the age group of $10-11$, especially the female group of our study shows more weight gain. Weight gain of LIG of present study shows lower values than values of LIG of Dutta. Weight gain of LIG of present study and the study of S. Chatterjee group are similar.

Present study had been undertaken with the view to comprehend the dynamics of various measurements and indices between the LIG and HIG and also to understand the sexual dimorphism presented by the measurements

\section{Conclusion}

Present study shows that there was a difference in growth rate between the different age groups i.e. 910, 10-11, 11-12 years in the LIG as well as in HIG. There was a significant difference between boys and girls in these age groups and socio-economic groups. Girls of both HIG and LIG show growth spurt in Height earlier than boys of HIG and LIG. In almost all studies we have observed that HIG values are always greater than LIG values in all the age groups. The growth of LIG can be increased up to the growth of HIG with nutritional supplements.

The data would be useful to understand the growth pattern in school children of age group of 9-12 years as influenced by the socio-economic factors

\section{References}

[1]. K. E. Elizabeth. Nutrition and Child development (Paras, $\left.2^{\text {nd }} e d, 2002\right)$ 37-184.

[2]. Standring, S, Gray'sanatomy, The anatomical basis of clinical practice (London UK, Elsevier Churchill Livingstone, 38th ed, 1995) 365-373.

[3]. Standring, S, Gray'sanatomy, The anatomical basis of clinical practice (London UK, Elsevier Churchill Livingstone, 39th ed, 2005).211-223.

[4]. I.C.M.R: ' Studies on growth and physical development of Indian infants and children'; Tech. Rep. Series No. 1960, 18.

[5]. Bhargava I and Sharma J. C, Anthropometric study of Barelas of Madhya Pradesh.Jour. Of Anatomical Soc. Of India, 8, 1959, 4344.

[6]. Singh Raghbir, A cross-sectional study of growth in five somatometric traits of Punjabi boys aged 11 to 18 years. Amer. J. Phys. Anthrop., 3, 1970, 129-138.

[7]. Gupta V M, Murthy N. S, Tiwari I. C. and Marwah S.M, Correlation study of weight, height and mid arm circumference in infants. Ind. J. Med. Res. 62, 1974, 1678-1681.

[8]. Currimbhoy L, Growth and development of Bombay children. Indian J. ChildHealth. 12, 1967, 393.

[9]. Phadke M. V,Growth norms in Indian children. Ind. J. Med. Res. 56, 1968, 850-857.

[10]. Mohanta K. D, Panda T.N. PraharajK.C,Anthropometric measurements of children of Western Orissa. Indian J. Pediatrics. 39, 1972, 12-14.

[11]. Bhandari B, Jain A. M, Karna P, Mathur A and Sharma V. K, Nutritional Anthropometry of rural school children of Udaipur district.,Indian ,J. Pediatrics. 59, 1972, 1.

[12]. Vijayaraghavan K, Darshan Singh and Swaminathan M.C,Height and Weight of well-nourished Indian school children. Ind. J. Med. Res. 59, 1971, 648-658.

[13]. Agarwal K. M. et al,,Physical growth of adolescence.Indian Pediatrics, 11, 1974, 93-97.

[14]. Bhasin S. K. et al,,Skin fold thickness in well-nourished school children in Haryana. Indian Pediatrics; 27, 1990, 815-819.

[15]. N. K. Dutta et al, Growth pattern of Indian school children in relation to nutrition and adolescence. Ind. J. Med. Res., 62, 1972, 995 to 1001 .

[16]. Nag Anjali, Nag P. K and Chinthari S .G, Anthropometrics of small-scale industrial women workers. Ind. J. Med. Res. 86, 1987, 237-245.

[17]. Mahajan B. K. and Gupta M. C.Textbook of Preventive and Social Medicine, (Jaypee Brothers, $3^{\text {rd }}$ edition) $329-369$.

[18]. Satpati Chatterjee, Anindita Mandal, Physical growth pattern of girls (9-7 yrs.) from rural West Bengal. Ind. J. Med. Res.94, 1991, 346-350.

[19]. Vermaetal, Growth profile of preschool children in an Indian rural Community E Journal of Epidemiology and Community Health, 34, 1980, 59-64. 